\title{
Some veterinary aspects of the eradication of brucellosis
}

\author{
A. MCDiaRmid \\ D.Sc., Ph.D., M.R.C.V.S., F.R.C.Path., F.R.S.E. \\ Agricultural Research Council Institute for Research on Animal Diseases, \\ Compton, Newbury, Berkshire
}

\begin{abstract}
Summary
An outline is given of some criteria which must be met for the eradication of brucellosis in this country. The incidence of this zoonosis and the financial loss it causes are considered, along with the ultimate benefits to be derived by the farming industry and public health from its eventual eradication.

Diagnostic tests, vaccination policy, financial incentives, educational methods, the question of notification, and the necessity for full collaboration between the medical and veterinary professions are discussed in relation to the problem as a whole.

The debates in the House of Commons and the House of Lords are mentioned as historic landmarks in the campaign against brucellosis in this country, and the progress of the present eradication scheme is summarized.
\end{abstract}

IN order to eradicate an animal disease, particularly brucellosis, which is so difficult to cope with, certain criteria must be met:

(1) Prospective benefit from eradication must be shown for the country as a whole.

(2) The overall incidence of the disease must be determined by national surveys.

(3) Financial losses shown by the above surveys must convince the Treasury that eradication would be a profitable exercise.

(4) Diagnostic tests should be reliable and easy to apply.

(5) The eradication plan must be practical and ultimate success assured.

(6) Vaccination may be necessary to cope with an initial high incidence of disease and reduce it to a level at which a final 'test and slaughter' policy becomes a feasible proposition.

(7) Adequate evidence must be forthcoming that the disease is basically one of cattle and man, and that no other animals, domesticated or wild, are affected, except perhaps in rare instances through contact with infected cattle.

(8) A public awareness must exist of the dangers of this disease to the human population as well as to animals; the farming community as a whole mus appreciate the true value of eradication in the broadest sense.

(9) Financial incentives must be offered to enc courage farmers to establish and maintain their herds free from brucellosis.

(10) Full co-operation must be established between the veterinary and medical professions - a two-way notification system would be a practical step in this direction.

Some of these points were in fact raised by the joint medical and veterinary Oxford Working Group on Brucellosis (Bothwell et al., 1962). Unfortunate so far as brucellosis is concerned, action has beein extremely slow in the application of research res(its in practice.

These various points can now be considered in somewhat greater detail.

(1) The ultimate benefit to the country as a wholo from eventual eradication can be assessed on the following broad basis. Firstly, more calves and more milk will be produced and infertility will diminish The general health of the herds will improve and there will be much less disturbance to general farm ing policy-the prospects for the exportation of pedigree cattle and for carcases will also be better. Secondly, human brucellosis will be eliminated. A고. the cases diminish, so will there be an increase productivity with the reduction in the number of man hours lost through this disease. Costs to the National Health Service will be reduced. Thirdly benefits will accrue from eradication in other fringe spheres. For example, one case of brucellosis in thoroughbred mare, leading to abortion and the loss? of a foal, could represent a loss of many thousands op pounds. Several cases have occurred in this class of animal in recent years, but the economic overall lose is difficult to determine.

(2) The national incidence of the disease has if recent years been assessed at about $25 \%$ of the dairy herds, with $2 \%$ of the individual cattle affected Thus, prior to the initiation of the voluntary eradie cation scheme, 70,000 cattle were infected. Thब 
incidence of the disease varied greatly from one part of the country to another; some areas were virtually free, others had a much higher incidence than the national average.

(3) The financial loss has been variously assessed at $£ 2, £ 3$, and even $£ 5$ million per year, for the country as a whole. These are, of course, arbitrary figures, as it is quite impossible to assess human suffering attributable to this disease and the consequent loss to national production, but there can be little doubt of the vast benefit which would accrue from eradication. In order to convince the Treasury it was necessary to obtain support from both the House of Commons and the House of Lords. It is unfortunate that the veterinary profession has no M.P. within its own ranks to deal with matters such as this, and it fell to T. P. G. Kitson, M.P., to put the case for eradication. This happened 9 years ago and, in addition, he has asked innumerable questions on the subject over this period. Fortunately, he managed to secure a whole day's debate in the Commons and to his credit succeeded in getting the following motion accepted: 'That this House takes note of the continued existence of the condition known as brucellosis in cattle in this country, takes note of Her Majesty's Government's efforts to reduce the incidence of the disease through the calfhood vaccination scheme and the free calf vaccination scheme and hopes that, in view of the transmissibility of the disease to man, Her Majesty's Government will consider introducing further measures designed to eradicate the disease in cattle' (Hansard, 1964). This was the first real step towards Government support for an eradication plan.

Later, Baroness Summerskill again raised the subject in the House of Lords and they debated the situation on two separate occasions (Hansard, 1966, 1970). These reports contain detailed information about the brucellosis situation as a whole and are well worth reading. Quite apart from the very serious nature of this subject, glimmers of humour broke through the somewhat austere atmosphere in the Lords as, for example, when Lord Balerno, listing several countries where brucellosis was not a problem, mentioned the Virgin Islands, and another noble Lord rose immediately to point out that he would hardly have expected a problem of abortion to exist there in any case!

The national and the farming press, sound and television services of the B.B.C. and I.T.V. have all helped to stress the importance of this disease. Just how useful this publicity has been is, of course, difficult to assess, but at least some impact must have been made, as people now use the word 'brucellosis' instead of 'contagious abortion' and 'undulant fever', two very misleading terms under present day conditions.
In 1959 the Oxford Working Group on Brucellosis was formed. Veterinary and medical personnel pooled their resources and many of the findings of that group have been quoted in parliamentary debates. Quite apart from determining the herd and individual incidence in cattle in Oxfordshire and Berkshire, thousands of blood samples were collected from urban and rural populations. Tonsillar tissue was examined from children living in contact with confirmed diseased herds and placentae were obtained from women who had shown high levels of antibody to Br. abortus at the pre-natal clinics. It was remarkable that in this instance no cultures of $B r$. abortus were obtained either from the tonsils or the placentae.

Several papers were subsequently produced drawing attention to various aspects of the brucellosis problem. Leading articles were written for the medical journals and some were subsequently quoted at length in the parliamentary debates, particularly in the House of Lords. It is interesting to recall that one survey on the Isle of Wight showed that the overall rate of infection among the 520 registered herds on the island was $6.3 \%$ in 1959 (Brodigan et al., 1961). Only two or three individual cattle were infected on each farm. Eradication of the disease would have been feasible without a great deal of expense and, in retrospect, it is a pity that eradication was not undertaken at that time.

(4) So far as the diagnostic tests are concerned, it is always worth while remembering that several countries have succeeded in eradicating brucellosis, mainly on the basis of individual blood serum agglutination tests and herd milk ring tests, coupled with a good calfhood vaccination programme with S19. Sometimes vaccination has not been required because of a low initial incidence of the disease. Undoubtedly the milk ring test is still valuable for screening milking herds. It is extremely unlikely that brucellosis will be found in any herd which has given three consecutive negative MRT's at reasonable intervals on churn samples. The principal difficulties associated with this test are the bulk tanker, residual effect of S19 over-age vaccination, and young animals aborting in their first pregnancies before they have contributed to the milk supply. The Ministry of Agriculture has decided to use the Rose Bengal plate test (RBPT) as their principal test. This is a modification of the original Brewer card test, employed in the U.S.A. for many years, both for porcine and bovine brucellosis diagnosis. The test, as used in America, is essentially a 'crush side' test, that is the cattle are tested in the field and the results are known before the veterinary surgeon leaves the farm. In this country, blood sera, collected from cattle in the usual way, are submitted to a laboratory for the RBPT. There are no 'doubtfuls' with this test, the 
animals either pass or fail. If they fail, they are subjected to the complement fixation test (CFT), which has been shown to be more reliable than the blood serum agglutination test (SAT). At present this testing procedure is confined mainly to the laboratory, so far as the Ministry of Agriculture is concerned. However, veterinary surgeons in country practice might be able to help the eradication programme by identifying potentially infected animals on the farms by the RBPT, which is over sensitive anyway, thus rendering the chance of missing an infected animal remote. It has been said that the widespread use of the RBPT could reduce the time necessary for eradication in this country by at least 3 or 4 years. No tests are, however, infallible and it is always possible to find a long-standing case, still excreting organisms, which will fail to react to any of the serological tests. In fact the first herd to be entered on the Ministry's register of accredited herds had just this problem and it took a great deal of time and effort to track down the offender, one of the oldest cows in the herd, by biological testing of a large series of milk samples in guinea-pigs. Incidentally, it is interesting to note what has happened in the Channel Islands where brucellosis has been absent for a very long time and where there is no vaccination with S19. No animals react to the CFT and those reacting to the SAT are invariably below the acceptable diagnostic level in this country.

(5) The overall plan for eradication must, of course, be so designed that it does not interfere with the general cattle trade of the country; for example an immediate 'test and slaughter' policy would have been quite impracticable because of the lack of suitable replacement stock. The cattle industry in Britain is highly dependent on the movement of animals from one area to another and the imposition of immediate area restrictions could cause considerable inconvenience to the farming community; the plan for eradication must, therefore, depend on a more gradual build-up of clean stock to provide replacements to herds which are in the process of eradicating the disease. The ultimate success of the scheme must, of course, be assured in order to receive the necessary financial backing from the Government, even if this might, eventually, necessitate the slaughter of a few entire 'problem' herds within the next few years.

(6) Some countries, as already stated, have been fortunate in having a very low initial incidence of the disease, which enabled them to bring in an immediate 'test and slaughter' policy, but other countries with an incidence similar to our own, that is about $25 \%$ of the dairy herds and $2 \%$ of the individual cattle, have found it necessary to embark on a very comprehensive vaccination scheme to reduce this level to reasonable proportions prior to a 'test and slaughter' policy being introduced. Vaccination with S19 can never by itself eradicate

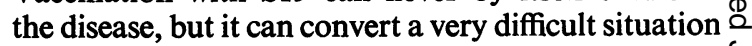
into one which can be coped with. The vaccine must, $\stackrel{\hookrightarrow}{\hookrightarrow}$ of course, always be of impeccable quality; it is just $\overrightarrow{\bar{s}}$ as easy to manufacture a bad batch of vaccine as a $\overrightarrow{0}$ good one and the system for testing the final product $\frac{C}{\circ}$ must be constantly watched for any developing $\overline{\frac{D}{2}}$ faults. Compulsory vaccination of young calves, 3-6 $\bar{\varnothing}$ months of age, has been recommended by many individuals and organizations. The argument against $\omega$ this has been basically the difficulty of policing the $\vec{O}$ situation, not a shortage of vaccine, but even if incomplete vaccination had occurred, for example, $\vec{\omega}$ at a level of $80 \%$ some years ago, this would un-doubtedly have greatly helped to reduce the overall rate of infection in the national herd at the present time. For many years, with a voluntary 0 vaccination scheme, the level was about $50 \%$ of those calves of an age which could have been vaccinated, not by any means good enough for the prelude to an eradication scheme. The killed adju-o vant vaccine prepared from the British strain 45/20, which is practically non-agglutinogenic, has proved $\square$ itself invaluable for the immunization of animalso which are too old for vaccination with S19, such ases adult cattle of breeding age imported from Ireland. $\vec{\omega}$ Moreover, immunity can be established rapidly inga herd by the vaccination of all stock over 6 mont of age in the face of an immediate heavy challengeo of infection. There are, of course, complications with serological testing following 45/20 vaccinationo superimposed on an existing S19 vaccination. Someô๊ animals show a persisting positive CFT for as longe as 18 months, but the complications are minimal in $\overrightarrow{\overrightarrow{0}}$ the absence of previous S19 vaccination. Fortunately 3 $99.5 \%$ of calves vaccinated with S19 before 6 months of age are negative to the CFT 6 months later.

(7) In the proposed eradication areas it is im=을 portant that adequate evidence should be produced to show that no other animals, apart from cattle $\frac{0}{3}$ are affected with brucellosis. It would be futile to attempt to eradicate the bovine disease when, for? instance, in-contact wild mammals such as deer, hares, rats, etc. are infected. Fortunately, work응 carried out over the last 20 years at Compton has shown that any cases of brucellosis in animals other than cattle are purely accidental and that, so far as we know, there are no natural reservoirs of infection in this country, unlike some other countries where the infection exists endemically in wild ungulates and small wild mammals.

(8) No eradication scheme can succeed withoufe the backing not only of the people immediately concerned, namely the farming community, but also the public as a whole. It is important that the public should be made fully aware of the danger to the 
urban community from this disease, through drinking unpasteurized milk and also the risk of infection, from direct contact with infected animals, to farm workers, veterinary surgeons and slaughterhouse personnel. The ultimate value of eradication should be appreciated by all sections of the community.

(9) Financial incentives were suggested many years ago by the Oxford Working Group and it is gratifying to see that such incentives are now being offered by the Ministry of Agriculture at the rate of $0.8 p$ per gallon of milk and $£ 5$ per head for beef cattle, annually. This should do much to stimulate farmers to eradicate brucellosis from their herds as soon as possible.

(10) Full co-operation must always be fostered between the medical and veterinary professions. It is possible that a two-way notification system for this disease would be a practical step in the right direction. Much argument has ensued about this point, based mainly on the alleged difficulty of diagnosis of the disease in the human subject. Nevertheless, the occurrence of brucellosis in man is, without doubt, an infallible indication of the presence of infection in a milk supply or the individual's contact with an infected animal, and again the confirmation of the presence of the disease in the herd should act as an immediate warning to all concerned about the possibility of concomitant human cases occurring in that particular area.

Many of these points were raised by the Oxford Working Group and various other organizations as long ago as 1960 . It is to be regretted that, at the present time, after all the research effort which has been put into brucellosis in this country and elsewhere, and the number of committees which have deliberated on this subject, the Scottish press are reporting that human reactors are being notified in Scotland at the rate of one a day. Naturally, not all of these are exhibiting clinical symptoms, but here at least is direct evidence of the considerable risk to the population as a whole. There can be no doubt that the figures of $150 / 200$ human cases per year, produced by the Ministry of Health for many years, could be an underestimate of the true situation. Just how many more human cases will arise before the disease is finally eradicated from this country is difficult to estimate.

Although, until recently, progress towards eradication has been slow, considerable improvement has occurred within the last 2 or 3 years. The number of herds in the voluntary scheme as at September 1972 was 70,000 . Of these, 44,000 are now accredited, the rest are in the qualifying stages. In practice, this means that about 1000 herds are joining the scheme every month, and that probably about one third of the herds in the country are now officially certified free from the disease. November 1972 saw the beginning of compulsory 'test and slaughter' in certain areas throughout the country. These areas were pre-selected on the basis of their relative freedom from the disease; i.e. about $75-80 \%$ of the herds being already in the scheme. The main areas involved are the North-West of Scotland, the North-West of England, South-West Wales and the Isle of Wight. At the present rate of progress, however, it seems likely that it will take about 10 years to eradicate the disease from the entire cattle population.

\section{References}

Bothwell, P.W., McDiarmid, A., Bartram, H.G., MackENZIE-Wintle, H.A. \& Williamson, A.R.H. (1962) Brucellosis control and eradication: notes and proposals of the Oxford Working Group. Veterinary Record, 74, 1091.

Brodigan, M., McDiarmid, A., Mann, P.G. \& Skone, J.F. (1961) Brucellosis-an island epidemiological study. British Medical Journal, 2, 1393.

Parliamentary Debates, House of Commons. (1964) Hansard, 696, no. 125, 1702.

Parliamentary Debates, House of Lords. (1966) Hansard, 276, no. 43, 754.

Parliamentary Debates, House of Lords. (1970) Weekly Hansard, no. 747, 307, no. 27, 72. 